\title{
BIOPRODUTOS A PARTIR DO ÓLEO VEGETAL RESIDUAL: VELA, GIZ E MASSA DE MODELAR
}

\author{
Bioproducts production from Vegetable Oil Residual: Candle, Chalk and Modeling clay \\ Sérgio Thode Filho', Ana Paula da Silva da Costa ${ }^{2}$, Israel Rodrigues ${ }^{3}$, \\ Marcelo Fonseca Monteiro de Sena ${ }^{4}$, Elmo Rodrigues da Silva ${ }^{5}$

\begin{abstract}
'Doutorando em Meio Ambiente pelo PPG-MA da Universidade do Estado do Rio de Janeiro - UERJ, Professor do Instituto Federal de Educação, Ciência e Tecnologia do Rio de Janeiro - IFRJ, Campus Duque de Caxias, RJ, Laboratório Multidisciplinar de Gerenciamento de Resíduos - LMGR

${ }^{2}$ Aluna do Curso Tecnólogo em Gestão Ambiental (CEFET-RJ), bolsista pesquisadora do LMGR

${ }^{3}$ Aluno do Curso Técnico em Química - IFRJ, colaborador do LMGR

${ }^{4}$ Professor do Instituto Federal do Rio de Janeiro - IFRJ, Campus Duque de Caxias, RJ - LMGR

${ }^{5}$ Professor do PPG-MA da Universidade do Estado do Rio de Janeiro - UERJ
\end{abstract}

\section{Resumo}

O óleo vegetal de reuso é um resíduo altamente impactante ao ambiente e que possui um alto valor agregado mesmo após o seu consumo. O objetivo deste trabalho é apresentar a obtenção de três bioprodutos como alternativa mitigadora do impacto ambiental, provocado pelo descarte inadequado do óleo vegetal residual. Para produção da vela foi utilizado $50 \mathrm{~mL}$ de óleo vegetal residual e $40 \mathrm{~g}$ de estearina, ambos foram unidos a frio em um béquer de $200 \mathrm{~mL}$. Para produção do giz foi utilizado $10 \mathrm{~mL}$ de óleo vegetal residual, $20 \mathrm{~g}$ de estearina e $0,35 \mathrm{~g}$ de pigmento para vela. Ambos foram unidos a frio em um béquer de $200 \mathrm{~mL}$. Para produção da massa de modelar foi utilizado $12 \mathrm{~g}$ de farinha de trigo, $12 \mathrm{~g}$ de amido de milho, $6 \mathrm{~g}$ de sal, $6 \mathrm{~g}$ de carbonato de cálcio, $15 \mathrm{~mL}$ de óleo vegetal residual, $25 \mathrm{~mL}$ de água, $2,25 \mathrm{~mL}$ de corante alimentício. O resultado do processamento descrito na metodologia é um material com características físicas aceitáveis, sem migração de óleo, possibilitando ser modelado e decorado. Pôde-se concluir que estes bioprodutos são vantajosos do ponto de vista econômico e ambiental. Outro aspecto importante é a utilização de materiais residuais na sua composição o que permite um ciclo de vida estendido a estes materiais que outrora seriam descartados inadequadamente ou potenciais poluidores do ambiente e do meio urbano.

Palavras chave: Bioprodutos, vela, giz, massa de modelar.

\begin{abstract}
The vegetable oil is a highly impactful reuse waste to the environment and have a high value even after consumption. The objective of this work is to obtain three alternative bioproducts such as mitigating the environmental impact caused by the improper disposal of waste vegetable oil. For production of the candle was used $50 \mathrm{~mL}$ of residual vegetable oil and $40 \mathrm{~g}$ of stearin, both were united into a cold beaker $200 \mathrm{~mL}$. For the production of chalk $10 \mathrm{~mL}$ of residual vegetable oil, $20 \mathrm{~g}$ stearine and $0.35 \mathrm{~g}$ of pigment was used for sailing. Both states were cold in a $200 \mathrm{~mL}$ beaker. For mass production model used was $12 \mathrm{~g}$ wheat flour, $12 \mathrm{~g}$ of corn starch, $6 \mathrm{~g}$ of salt, $6 \mathrm{~g}$ of calcium carbonate, $15 \mathrm{~mL}$ of residual vegetable oil, $25 \mathrm{~mL}$ of water, $2.25 \mathrm{~mL}$ food coloring. The result of processing methodology is described in a material with acceptable physical properties without migrating oil, allowing be patterned and decorated. It was concluded that these bioproducts are advantageous from an economic and environmental perspective. Another important aspect is the use of waste materials in their composition which allows for extended cycle sold with these materials that would otherwise be discarded inappropriately or potential polluters of the environment and urban environment.
\end{abstract}

Keywords: Bioproducts, candle, chalk, modeling clay. 


\section{INTRODUÇÃO}

Uma das alternativas para o reuso do óleo vegetal residual de fritura é o processo de saponificação, ou seja, produção de sabão. O sabão é um produto obtido a partir de uma hidrólise alcalina (saponificação) de uma gordura de origem vegetal ou animal. Os óleos vegetais são constituídos predominantemente de substâncias como triglicerídeos, formados por ésteres com base em ácidos carboxílicos de cadeia longa (ácidos graxos) e glicerol. Sendo assim, a produção de sabão a partir de óleos residuais pode auxiliar na mitigação dos impactos ambientais associados ao óleo vegetal residual de fritura (FRANCO et al., 2009; SABESP, 2011).

Além dos saponáceos, como sabão em barra, detergente líquido e sabão pastoso, o óleo vegetal residual pode ser matéria prima para outros produtos tais como: biodiesel, óleo para engrenagens, glicerina automotiva, tintas, etc. (NOGUEIRA \& BEBER, 2009; WILDNER \& HILLIG, 2012).

O óleo vegetal de reuso é um resíduo altamente impactante ao ambiente e que possuem um alto valor agregado mesmo após o seu consumo. Percebe-se que cresce a cada dia o número de Arranjos Produtivos Locais no Brasil, porém dos estados da região Sudeste, nenhum se interessou ou teve um olhar mais abrangente para a questão do óleo vegetal (THODE-FILHO et al., 2013a). O objetivo deste trabalho é apresentar a obtenção de três bioprodutos como alternativa mitigadora do impacto ambiental, provocado pelo descarte inadequado do óleo vegetal residual.

\section{METODOLOGIA}

O óleo vegetal residual utilizado neste trabalho foi oriundo de doações voluntárias de moradores de diversas localidades do Município de Duque de Caxias, Rio de Janeiro. O material foi entregue, necessariamente acondicionado em garrafas polietileno PET de $500 \mathrm{~mL}$ a $2 \mathrm{~L}$ no posto de entrega voluntária situado no Laboratório Multidisciplinar de Gerenciamento de Resíduos (LMGR), no Instituto Federal de Educação, Ciência e Tecnologia do Rio de Janeiro campus Duque de Caxias. No laboratório, procedeu-se com a filtração do óleo doado para retirada dos resíduos sólidos e em seguida acondicionado por um período de dez dias em um tanque de 100L para decantação. Após estes processos físicos iniciais procederam-se dois testes químicos que foram o índice de acidez com $2,15 \%$ e o índice de peróxido com $1,85 \mathrm{meq} / \mathrm{kg}$. Após estes processos iniciou-se a produção dos bioprodutos. Os materiais utilizados para produção da vela, giz e massa de modelar foram: béquer de $200 \mathrm{~mL}$, bastão de vidro, forno de micro-ondas, espátula, óculos, luva e máscara de segurança. Os reagentes utilizados foram: óleo vegetal residual, estearina em escama, pigmento para velas, aroma, farinha de trigo, sal, corante alimentício, amido de milho e carbonato de cálcio.

\section{I Produção da vela}

Para produção da vela (Figura 1a) foram utilizados $50 \mathrm{~mL}$ de óleo vegetal residual e $40 \mathrm{~g}$ de estearina, ambos foram unidos a frio em um béquer de $200 \mathrm{~mL}$. A mistura foi aquecida no micro ondas, com potência média, em três etapas de 30 segundos. Tempo total de 1 minuto e 30 segundos. A cada 30 segundos de aquecimento o material era retirado para proceder uma leve homogeneização com bastão de vidro. Após o material estar no estado líquido e homogêneo, adicionou-se um pavio de barbante e acondicionou-se em uma forma de PVC para resfriamento.

\subsection{Produção do giz}

Para produção do giz (Figura 1b) foram utilizados $10 \mathrm{~mL}$ de óleo vegetal residual, $20 \mathrm{~g}$ de estearina e $0,35 \mathrm{~g}$ de pigmento para vela. Os insumos foram unidos a frio em um béquer de $200 \mathrm{~mL}$. A mistura foi homogeneizada em temperatura ambiente no próprio béquer. Posteriormente, a mistura foi aquecida no micro ondas em 4 etapas de 30 segundos, totalizando um tempo total de 2 minutos. A cada 30 segundos de aquecimento o material era retirado do micro ondas para uma leve homogeneização com bastão de vidro. Após o material se encontrar em estado líquido e homogêneo adicionou-se em uma forma plástica para resfriar gradualmente em temperatura ambiente.

\subsection{Produção da massa de modelar}

Para produção da massa de modelar (Figura 1c) foram utilizados $12 \mathrm{~g}$ de farinha de trigo, $12 \mathrm{~g}$ de amido de milho, $6 \mathrm{~g}$ de sal, $6 \mathrm{~g}$ de carbonato de cálcio, $15 \mathrm{~mL}$ de óleo vegetal residual, $25 \mathrm{~mL}$ de água, $2,25 \mathrm{~mL}$ de corante alimentício. Todos os insumos secos foram misturados com uma colher em um Becker de $1000 \mathrm{~mL}$, após a mistura adicionou-se o óleo vegetal, a água e o corante, o material foi homogeneizado até obter uma consistência possível de ser sovada com as mãos. Sovou-se até a massa ficar homogênea e no ponto de modelar. Após a massa ficar homogênea e no ponto de modelar, a mesma foi envolvida em um plástico sem contato direto com o oxigênio. 


\section{RESULTADO E DISCUSSÃO}

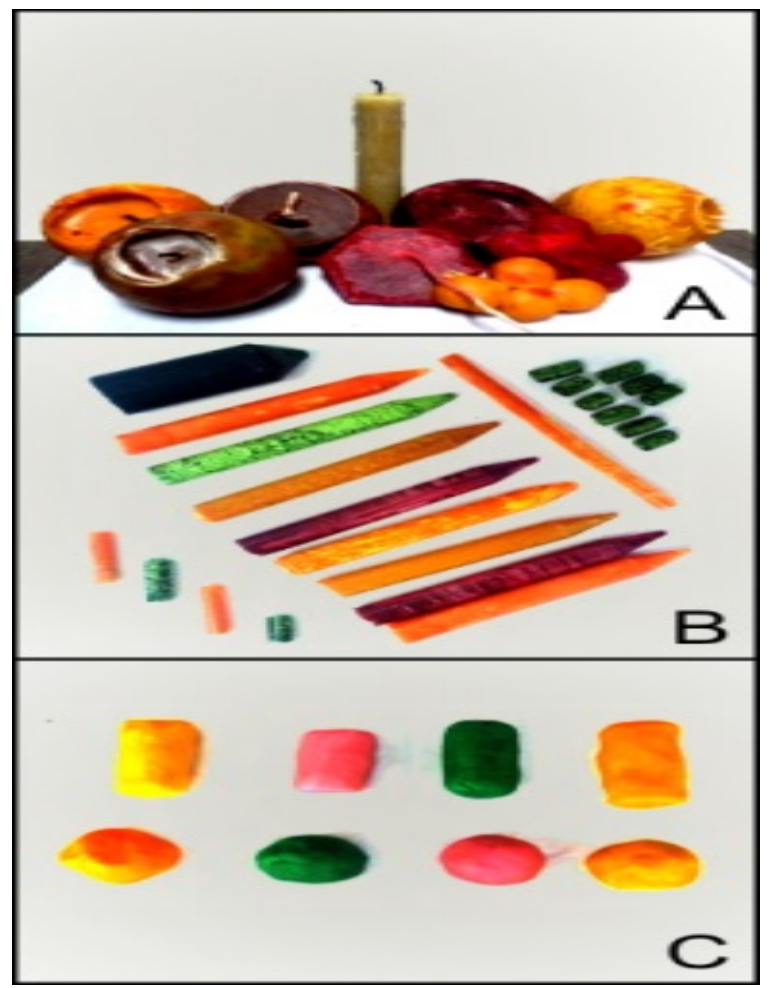

Figuras 1A. vela, 1B. giz , 1C. massa de modelar.

Após o processo metodológico efetivado produziram-se vela, massa de modelar e giz com desempenho semelhante aos vendidos comercialmente (Figuras 1a-c).

O custo dos insumos associado à obtenção dos bioprodutos é extremamente baixo, pois os equipamentos necessários para a produção são facilmente encontrados em um ambiente doméstico. Os mesmos são descritos na sequência a seguir: vela (Tabela1), Giz (Tabela 2) e massa de modelar (Tabela 3).

A vela para uso geral é produzida com parafina oriunda da destilação do petróleo e pavio de barbante encerado. O produto é comumente encontrado em caixa com oito unidades de $25 \mathrm{~g}$ cada. A caixa com oito unidades custa, em média, $\mathrm{R} \$ 5,00$. Aplicando à regra de três para o cálculo, cada vela possui um preço de venda ao consumidor de $\mathrm{R} \$ 0,63$. A metodologia apresentada neste estudo propõe a obtenção de uma vela com óleo vegetal residual e uma massa final de $90 \mathrm{~g}$. O custo para produção desta massa é de 1,15 . No entanto, aplicando à regra de três para o cálculo da massa de $25 \mathrm{~g}$, o custo associado a vela seria de 0,32 .

O giz para uso geral é produzido com cera plástica, pigmento, veículo e carga. O produto é comumente encontrado em caixa com seis ou doze unidades de $4 \mathrm{~g}$ cada. A caixa com seis unidades custa, em média, $\mathrm{R} \$ 1,00$. Aplicando à regra de três para o cálculo, cada giz possui um preço de venda ao consumidor de $\mathrm{R} \$ 0,16$. A metodologia apresentada neste estudo, propõe a obtenção de um giz com óleo vegetal residual e uma massa final de $30 \mathrm{~g}$. O custo para produção desta massa

Tabela 1. Custo dos insumos associados a produção da vela.

\begin{tabular}{lcc}
\hline \multicolumn{1}{c}{ Insumos } & Quantidades & $\begin{array}{c}\text { Custo unitário } \\
(\mathrm{R} \$)\end{array}$ \\
\hline & & \\
Óleo vegetal residual & $50 \mathrm{ml}$ & - \\
Estearina & $40 \mathrm{~g}$ & $\mathrm{R} \$ 1,10$ \\
Pavio de barbante & 1 peça & $\mathrm{R} \$ 0,05$ \\
Custo total dos insumos & & $\mathbf{R} \mathbf{1 , 1 5}$ \\
\hline
\end{tabular}


Tabela 2. Custo dos insumos associados a produção do giz.

\begin{tabular}{lcc}
\hline \multicolumn{1}{c}{ Insumos } & Quantidades & $\begin{array}{c}\text { Custo unitário } \\
(\mathrm{R} \$)\end{array}$ \\
\hline Óleo vegetal residual & $10 \mathrm{ml}$ & - \\
Estearina & $20 \mathrm{~g}$ & $\mathrm{R} \$ 0,56$ \\
Pigmento para vela & $0,35 \mathrm{~g}$ & $\mathrm{R} \$ 0,05$ \\
Custo total dos insumos & & $\mathbf{R} \mathbf{0 0 , 6 1}$ \\
\hline
\end{tabular}

é de R\$0,61. No entanto, aplicando à regra de três para o cálculo da massa de $4 \mathrm{~g}$, o custo associado ao giz seria de $\mathrm{R} \$ 0,08$.

A massa de modelar é produzida com plástico, água, carboidratos de cereais, cloreto de sódio, cloreto de cálcio, hidrocarbonetos alifáticos, fragrância, pigmento alimentício, entre outros. $\mathrm{O}$ produto é comumente encontrado em caixa com seis unidades de $15 \mathrm{~g}$, totalizando $90 \mathrm{~g}$ a caixa. A caixa com seis unidades custa, em média, $\mathrm{R} \$ 1,50$. Aplicando à regra de três para o cálculo, cada massa possui um preço de venda ao consumidor de $\mathrm{R} \$ 0,25$. A metodologia apresentada neste estudo propõe a obtenção de uma massa de modelar com óleo vegetal residual, pesando $76 \mathrm{~g}$. O custo para produção desta massa é de $\mathrm{R} \$ 0,96$. Cada $12,5 \mathrm{~g}$ com custo de $\mathrm{R} \$ 0,15$. Neste sentido, $15 \mathrm{~g}$ da massa de modelar com óleo vegetal residual apresenta um custo de $\mathrm{R} \$ 0,18$, referente aos seus insumos.

Ao final de um minicurso intitulado produção de saponáceos como incentivo à reutilização do óleo vegetal residual, oferecido no IFRJ CDUC, percebeu-se que os problemas ambientais causados pelo descarte inadequado do óleo residual de fritura são desconhecidos por grande parte da população local, a rentabilidade dos produtos fabricados a partir do óleo residual de fritura é um dos principais fatores estimulantes do seu reaproveitamento, seguido pela facilidade de aplicação dos métodos de produção; os produtos fabricados possuem qualidade satisfatória e semelhança com os produtos industrializados, sendo um grande facilitador para a sua comercialização (THODE-FILHO et al., 2013b).

O óleo vegetal acondicionado em uma garrafa pet e descartado no lixo comum pode ser caracterizado como resíduo sólido, no entanto, se descartado pela pia de cozinhas domiciliares, comerciais ou industriais, vaso sanitário ou tanque de lavar roupas, passa a ser um efluente. Entende-se por efluente o termo usado para caracterizar os despejos líquidos provenientes de diversas atividades humanas ou processos (BRASIL, 2011).

Os efluentes de qualquer fonte poluidora somente poderão ser lançados diretamente nos corpos receptores após o devido tratamento e desde que obedeçam às condições, padrões e exigências. Percebe-se que no caso do óleo vegetal é feito lançamento direto, isto é, quando ocorre a condução direta do efluente ao corpo receptor, não passando por nenhum tipo de tratamento ou beneficiamento (BRASIL, 2011).

Apesar de um número bastante reduzido de segmentos e empresas utilizarem o óleo vegetal residual como matéria-prima de seus produtos, este número tende a aumentar em um futuro próximo devido às exigências na nova Política Nacional de Resíduos Sólidos no Brasil e dos prováveis incentivos governamentais (NOGUEIRA \& BEBER, 2009; BRASIL, 2010; WILDNER \& HILLIG, 2012).

Tabela 3. Custo dos insumos associados a produção da massa de modelar.

\begin{tabular}{lcc}
\hline \multicolumn{1}{c}{ Insumos } & Quantidades & $\begin{array}{c}\text { Custo unitário } \\
(\mathrm{R} \$)\end{array}$ \\
\hline Óleo vegetal residual & & - \\
Água & $15 \mathrm{ml}$ & - \\
Farinha de trigo & $25 \mathrm{ml}$ & $\mathrm{R} \$ 0,05$ \\
Amido de milho & $12 \mathrm{~g}$ & $\mathrm{R} \$ 0,10$ \\
Sal & $12 \mathrm{~g}$ & $\mathrm{R} \$ 0,01$ \\
Carbonato de cálcio & $6 \mathrm{~g}$ & $\mathrm{R} \$ 0,80$ \\
Custo total dos insumos & $6 \mathrm{~g}$ & $\mathbf{R} \mathbf{0 , 9 6}$ \\
\hline
\end{tabular}




\section{CONCLUSÃO}

Após a obtenção destes resultados, pôde-se concluir que estes bioprodutos são vantajosos do ponto de vista econômico e ambiental. Outro aspecto importante é a utilização de materiais residuais na sua composição o que permite um ciclo de vida estendido a estes materiais que outrora seriam descartados inadequadamente ou potenciais poluidores do ambiente e do meio urbano. Sugere-se, a partir dos resultados deste estudo, a possibilidade de avaliar as potencialidades de implantação de uma cadeia produtiva de óleo vegetal residual, como forma de minimizar o impacto de seu descarte inadequado e possibilitar a geração de trabalho e renda, através de cooperativas organizadas de catadores.

\section{REFERÊNCIAS}

BRASIL. Lei $\mathrm{n}^{\circ} 12.305$, de 2 de agosto de 2010. Institui a Política Nacional de Resíduos Sólidos; altera a Lei no 9.605, de 12 de fevereiro de 1998; e dá outras providências.

BRASIL. Resolução nº 430 de 13 de maio de 2011. Dispõe sobre as condições e padrões de lançamentos de efluentes, complementa e altera a Resolução $n^{\circ}$ 357, de 17 de março de 2005, do Conselho Nacional do Meio Ambiente - CONAMA.

FRANCO, R.; FREIRE, M.; ALMEIDA, M. F. Reaproveitamento do óleo vegetal utilizado em frituras para produção de sabão. 2009. In. IV Congresso de Pesquisa e Inovação da Rede Norte e Nordeste de Educação e Tecnologia, Belém, PA.

NOGUEIRA, G. R.; BEBER, J. Proposta de metodologia para o gerenciamento de óleo vegetal residual oriundo de frituras. Tese de Mestrado em Bioenergia. Universidade Estadual do Centro-Oeste do Paraná, Irati. 2009. Disponível em: <http://www. unicentro.br>. Acesso em: 14 abr. 2012.

SABESP. Reciclagem de óleo de cozinha, 2011. Disponível em: <http://site.sabesp.com.br>. Acesso em: 14 abr. 2012.

THODE-FILHO, Sergio; SANTOS, Aline Santiago; ALMEIDA, Thuanny Moraes de; SILVA, Elmo Rodrigues. (2013a) Tecnologia ambiental aplicada ao gerenciamento e processamento do óleo vegetal residual no estado do Rio de Janeiro. Revista Eletrônica em Gestão, Educação e Tecnologia Ambiental,
(15) $15,3026-3035$.

THODE-FILHO, Sergio; SENA, Marcelo Fonseca Monteiro de; SILVA, Elmo Rodrigues; SILVA, Felipe Bezerra da; SILVA, Luiz Gustavo Brandão da; OLIVEIRA, Bruno Freitas de. (2013b) Fabricação de saponáceos como incentivo à reutilização do óleo vegetal residual: um minicurso no IFRJ - campus Duque de Caxias. Conhecimento On-line, (2) 2, 1-7.

WILDNER, L. B. A.: HILLIG, C. (2012). Reciclagem de óleo comestível e fabricação de sabão como instrumentos de educação ambiental. Revista Eletrônica em Gestão, Educação e Tecnologia Ambiental, (1), 813-824.

\section{MINISTÉRIO DA AGRICULTURA, PECUÁRIA} E ABASTECIMENTO (MAPA). Agronegócio. Disponível em: http://www.agricultura.gov.br. Acesso em: 29 de outubro de 2012.

MINISTÉRIO DO DESENVOLIMENTO INDÚSTRIA E COMERCIO EXTERIOR (MIDIC). Secretaria de Comércio Exterior (SECEX). Disponível em: http://www. desenvolvimento.gov.br/sitio/interna/ interna.php? area $=5 \&$ menu $=1078 \&$ refr $=1076$. Acesso em: 12 de novembro de 2012.

RIGAUZ. L. R. Market Share analysis aplied to canadian wheat exports. Canadian Journal of Agricultural Economics, Orleans, v. 19, n. 1, p. 22-23, Jul. 1971.

RUBIN, L. S.; ILHA, A. S.; WAQUIL, P. D. O comércio potencial brasileiro de carne bovina no contexto de integração regional. Revista de Economia e Sociologia Rural. v. 46, n. 04, p. 1067-1094, out/dez 2008.

SILVA, F. A.; GOMES, M. F. M.; CORONEL, D. A.; GOMES, M. T. M. Competitividade das exportações brasileiras de mamão, 1995 a 2008. Revista de Economia e Sociologia Rural, v. 9, n. 3, p. 393-420, 2011.a.

SILVA, M. A. P.; ROSADO, P. L.; BRAGA, M. J.; CAMPOS, A. C. Oferta de exportação de carne de frango do Brasil, de 1992 a 2007. Revista de Economia e Sociologia Rural, v. 49, n. 1, p. 31-54, 2011.b.

SOUZA, S. S. Mudanças cambiais e o efeito dos fatores de crescimento das receitas de exportações brasileiras de soja. Revista de Economia e Agronegócio, Viçosa, v. 5, n. 1, p. 1-24, jan./mar. 2007 